\section{Ueber die Beziehungen der Moskitos zu den Malariaparasiten in Kamerun.}

Von Marinestabsarzt a. 1. s. Dr. Hans Ziemann in Victoria.

Von der Colonial-Abtheilung des Auswärtigen Amts zur Veröffentlichung übergeben.

Seit meiner Ankunft in Kamerun, Anfang März 1899, war das unablässige Bestreben darauf gerichtet, die ätiologische Bedeutung der Moskitos für die Malaria festzustellen. Es war bekannt, dass Kamerun, eine der gefährlichsten Malariagegenden, wenig von Moskitos heimgesucht war, wenigstens die Küstenplätze nicht. Trotzdem gelang es nach und nach 13 verschiedene Moskitoarten festzustellen, sowohl von der Gattung Culex, als von der Gattung Anopheles. Letzterer war damals auf der Jossplatte selbst nur vertreten durch einen dem Anopheles claviger nahestehenden Anopheles. Ich machte diese Entdeckung des Vorkommens des Anopheles an der westafrikanischen Küste schon Ende März 1899.

Ausserdem gelang es, Anhaltspunkte über die Vertheilung und Lebensbedingungen der meisten Arten zu finden. Dieselben dürften für die zu ergreifenden hygienischen Maassnahmen von grosser Bedeutung sein. Niemals wurden, um nur einiges herauszugreifen, Larven oder Puppen der Moskitos in schneller fliessendem Wasser, niemals im Wasser der sich bei Fluth mit Meerwasser anfüllenden, gesundheitlich sonst sehr verrufenen Creeks gefunden, immer nur, wie in Indien, in kleinen stehenden Wasseransammlungen. In Wässern mit 1,1\% Kochsalzgehalt wurden noch Larven und Puppen der Gattung Culex gefunden. Ein höherer Salzgehalt scheint die Entwickelung des Moskitos zu hemmen. In kleinen Tümpeln, die mit einer Rahmhaut bedeckt waren, fand keine Entwickelung der Larven mehr statt. Dünne Schichten von Petroleum hinderten in kurzem die weitere Entwickelung, ja führten sogar schnelles Absterben herbei. Stets waren die Puppen widerstandsfähiger als die Larven.

Trotz sorgfältiger Section vieler Hunderter von Moskitos gelang es auf der Jossplatte und auch flussaufwärts niemals, in den Speicheldrüsen und den Mägen frisch gefangener Culices oder Anopheles Formen zu finden, wie sie Ross und R. Koch bei Moskitos gefunden, die proteosomahaltiges Vogelblut gesogen, oder wie sie die Italiener Grassi, Bignami, Bastianelli in Moskitos nachgewiesen, die die sogenannten Halbmondformen und Sphären der menschlichen Malariaparasiten in sich aufgenommen hatten. Nur diese letzteren Formen können sich im Magen bestimmter Moskitos weiter entwickeln. Niemals konnte ich, in Uebereinstimmung mit den genannten Autoren, eine Weiterentwickelung der gewöhnlichen ringförmigen Parasiten der Febris tropica im Magen von Vertretern der Gattung Culex oder Anopheles finden. Den Grund für die obigen negativen Befunde fand ich bald darin, dass erstens die Proteosomainfection der Vögel, die zu Moskitoexperimenten zu verwenden war, hier äusserst selten war. Bei im ganzen 96 Vögeln fand ich diese interessante Infection nur zweimal. Beide Vögel starben noch dazu bald. Zweitens gehörte die Umwandlung der hiesigen Malariaparasiten in die Halbmond- und Sphärenform, die allein für Experimente mit Moskitos in Frage kamen, zu den grössten Ausnahmen.

Ich war oft nahe daran, an der Richtigkeit der Moskitotheorie zu zweifeln. Mit Sehnsucht und leisem Neide dachte ich an das Material, das den italienischen Forschern zur Seite stand, deren Patienten oft grosse Mengen von Halbmonden in ihrem Blute beherbergten. 'In weit mehr als 1000 Blutuntersuchungen konnte ich nur zwölfmal ganz vereinzelte Halbmonde nachweisen.1)

Filariaembryonen von der Gattung Filaria perstans wurden dagegen dreimal im Moskitodarme gefunden.

Die erwähnten grossen Schwierigkeiten, die sich gerade hier den Moskitountersuchungen entgegenstellten, wurden durch eine recht anstrengende Praxis nicht gerade gemildert. Längere Zeit war ich der einzige Arzt in Kamerun.

Da entdeckte ich kurz vor Beendigung meiner hiesigen Stellvertretung am 27. März 1900 im Magen eines mittelgrossen grauen Culex, dessen Bestimmung ich mir vorbehalte, eine grosse Anzahl Coccidien ähnlicher Gebilde verschiedener Grösse, wje sie Ross und R. Koch in mit Proteosoma inficirten Mücken bereits nachgewiesen.

Ausserdem gelang es, am 29. März in zwei frisch gefangenen

1) Erwähnenswerth ist vielleicht, dass die Zeit von Mai bis October 1899 eine für Kameruner Verhältnisse relativ gesunde war.
Anopheles, nahestehend dem erwähnten Anopheles claviger, zwei Gebilde zu finden, die wohl als früheste Jugendformen von Malariacoccidien zu betrachten waren.

Damit war der Ansporn gegeben, die Moskitoversuche während meines kurz bemessenen Aufenthaltes in Victoria nach Kräften fortzusetzen.

$\mathrm{Nach}$ vielem Suchen in Häusern der Weissen und den Hütten der eingeborenen Bakweris fand ich endlich in den Wohnungen des Vorwerks einer Cacaoplantage zwei inficirte Anophelesarten.

Die eine entsprach der auch auf der Jossplatte vorkommenden Art, die andere war etwa $1 / 3$ kleiner, aber sonst der ersteren sehr ähnlich. $30 \%$ dieser dort gefangenen Anopheles waren mit jüngeren oder älteren Malariacoccidien, wie sie von den Italienern kürzlich beschrieben sind, inficirt. Eine schwarze Culexart mit weissen Ringen an den Beinen, die sich ebenfalls dort fand, war nie inficirt. Die drei weissen Bewohner des Hauses litten häufig an Febris tropica. Bei zweien konnte ich Halbmonde, wenn auch äusserst spärlich und nur zeitweise feststellen. Infectionsversuche mit aus Larven selbst gezüchteten Culices waren stets negativ. Dagegen gelang es, selbstgezüchtete Anopheles durch das Saugenlassen von halbmondehaltigem Blute zu inficiren. Anopheles, die keine Halbmonde in sich aufgenommen hatten, bezw. nur gesundes Blut gesogen, zeigten die Malariacoccidien niemals. Leider starben immer eine Anzahl der inficirten Anopheles, und ist daher mein Material noch recht klein.

Die wichtige Thatsache aber steht jetzt fest, dass auch in Kamerun sich der Parasit der Febris tropica im Anopheles-Magen zu einem pigmentirten, coccidienähnlichen Gebilde umwandeln kann, in dessen Innern sich dann die sogenannten Sporozoiten bilden. Diese gelangen schliesslich in die Speicheldrüsen, von wo sie durch den Stechrüssel wieder einem anderen Menschen eingeimpft werden können.

Ein glücklicher Zufall wollte, dass ich vor einigen Tagen auch Blut mit den Parasiten der gewöhnlichen, auch in Deutschland vorkommenden Tertiana zu beobachten hatte. Diese Parasiten sind hier äusserst selten, mindestens achtmal so selten wie in Ostafrika. In diesem Blute waren gleichzeitig auch die sogenannten Sphären des Tertianparasiten.

Nach drei Tagen hatten sich dieselben im Magen eines damit von mir inficirten Anopheles (nahestehend dem Anopheles claviger) zu. wenn auch spärlichen, Malaria-Coccidien umgewandelt. Bei dem geringen Material wage ich nicht zu entscheiden, ob die Malaria-Coccidien der gewöhnlichen Tertiana und der Tropica schon in diesem frühen Stadium Unterschiede zeigen.

Jedenfalls konnte ich bis jetzt an allen Malariaarten den Anopheles feststellen.

Die Untersuchungen über die Bedeutung der hier äusserst lästigen, sehr blutgierigen Sandfliegen blieben bis jetzt negativ.

Durch meine Feststellungen ist fürdie hygienischen Maassnahmen in Kamerun ein festeres Ziel gegeben worden, und ich werde meine bezüglichen Vorschläge in dem grösseren Berichte niederzulegen mir erlauben.

$\mathrm{Ob}$ die Moskitostiche den einzigen Modus der Malariaübertragung darstellen, müssen noch weitere Untersuchungen lehren, ebenso, ob der Mensch als einziges Wirbelthier den Malaraparasiten beherbergt. Eine kühle vorsichtige Behandlung dieser Fragen erscheint mir dopppelt angebracht bei der fiebernden Hast, mit der Malariauntersuchungen augenblicklich öfter vorgenommen werden.

Erwähnt sei noch, dass es mir gelungen ist, einen neuen Blutparasiten bei einer kleinen grauen Meerkatze zu finden, der dem Parasiten der Febris tropica sehr ähnlich ist. Eine Fortentwickelung dieser Affenparasiten konnte indess nicht gefunden werden. Ganz ähnliche Parasiten hatte ich schon vor fünf Jahren bei Fledermäusen in Kamerun festgestellt, also lange vor dem Italiener Deonisi. ${ }^{1}$ ) Dieselben wurden vor kurzem hier wiederum in Fledermäusen aufgefunden. Aber auch bei ihnen liess die Untersuchung der inneren Organe der Fledermäuse keine Fortentwickelung erkennen.

1) Cfr. Centralblatt für Bacteriologie 1896. 